\title{
JOGOS TEATRAIS COM DROGADICTOS: UMA INVESTIGAÇÃO-AÇÃO NA EDUCAÇÃO FÍSICA
}

\author{
THEATER GAMES WITH DRUG ADDICTS: AN ACTION-RESEARCH STUDY IN \\ PHYSICAL EDUCATION
}

JUEGOS TEATRALES CON DROGADICTOS: UNA INVESTIGACIÓN-ACCIÓN EN LA EDUCACIÓN FISICA

\author{
Sara Noêmia Cavalcanti Correia*, Pierre Normando Gomes-da-Silva**
}

\section{Palavras chave:} Educação Física. Jogos experimentais. Usuários de drogas.

Keywords:

Physical Education. Experimental

Games.

Drug Users.
Resumo: Este estudo objetivou investigar e descrever os significados relacionados ao Bem-estar Subjetivo relatados por drogadictos quando expostos a um programa de aulas com jogos teatrais. É uma pesquisa com abordagem qualitativa do tipo investigaçãoação. Dezoito jovens internos na Comunidade Terapêutica Fazenda da Esperança, em Alhandra/PB, fizeram parte deste estudo. Para realizar as observações foram aplicados um Roteiro de Observação de aula e o Roteiro de Entrevista Semiestruturada. Os jogos foram gravados em vídeo e os depoimentos das entrevistas em áudio. Foi possível observar e descrever com mais frequência relatos emocionais de bem-estar, liberdade para se expressar, alegria, felicidade e sentir-se vinculado ao grupo. Acredita-se que tais significados são justificados pela junção de estruturas pedagógicas de aula em que os momentos são didaticamente organizados em Sentir, Reagir e Refletir conjuntamente aplicados ao método Viola Spolin de jogos teatrais, com estruturação pela Pedagogia da Corporeidade.

Abstract: This study aimed to investigate and describe meanings related to subjective wellbeing reported by drug addicts when exposed to a program of classes including theater games. This is a qualitative action-research study whose participants were eighteen young clients of the Fazenda da Esperança therapeutic community in Alhandra, Paraíba, Brazil. It used Lesson Observation and a Semi-structured Interview Script. Games were recorded on video and interviews were recorded on audio. Emotional accounts of well-being, freedom for self-expression, joy, happiness, and bonds to the group were more often observed and described. Such meanings would be justified by the convergence of pedagogical class structures, when moments are didactically organized as Feeling, Reacting and Reflecting, jointly applied to the Viola Spolin theater games method, structured under The Pedagogy of Corporeity.

Resumen: Este estudio tuvo como objetivo investigar y describir los significados relacionados con el bienestar subjetivo reportado por adictos a las drogas cuando son expuestos a un programa de clases con juegos teatrales. Es un estudio cualitativo del tipo investigación-acción. Dieciocho jóvenes internos en la Comunidad Terapéutica Hacienda Esperanza, en Alhandra, Paraíba, formaron parte de ese estudio. Para llevar a cabo las observaciones se aplicaron un Plan de Observación de Clases y un Plan de Entrevista Semiestructurada. Los juegos fueron grabados en video y los testimonios de las entrevistas se grabaron en audio. Fue posible observar y describir con mayor frecuencia relatos emocionales de bienestar, libertad para expresarse, alegría, felicidad y de sentirse vinculado al grupo. Se cree que tales significados son justificados por la unión de estructuras pedagógicas de clase donde los momentos se organizan didácticamente en Sentir, Reaccionar y Reflexionar conjuntamente aplicados al método Viola Spolin de juegos teatrales, estructurados por la Pedagogía de la Corporeidad.
*Prefeitura Municipal de João Pessoa. João Pessoa, PB, Brasil. E-mail: sarinhanoemia@gmail.com

**Universidade Federal da Paraíba. João Pessoa, PB, Brasil.

E-mail: pierrenormandogomesdasilva@ gmail.com

Recebido em: 24-05-2017 Aprovado em: 18-08-2018

DOI: https://doi.org/10.22456/1982-8918.73526 (c) (1) (3) Licence 


\section{INTRODUÇÃOO}

Drogas, segundo a Organização Mundial da Saúde (OMS), podem ser definidas como qualquer substância não produzida pelo organismo que tem a propriedade de atuar sobre um ou mais de seus sistemas, produzindo alterações em seu funcionamento, sejam estas substâncias naturais ou sintéticas, lícitas ou ilícitas (CLASSIFICAÇÃO DE TRANSTORNOS MENTAIS E DE COMPORTAMENTO DA CID-10, 1993). Dentre a diversidade de drogas existentes na sociedade, há um grupo químico denominado psicotrópicos, que provocam alterações no Sistema Nervoso Central (SNC) e suas funções, induzindo temporariamente a sensações de prazer, de euforia, alívio de medo, de dor, de frustrações, de angústias, de forma que "o homem faz uso há milênios, de substâncias que sedam, embriagam e produzem alucinações" (GONÇALVES, 1988, p.10).

A drogadição se expressa pela adição frequente de uma ou mais substâncias psicoativas ao consumo no quotidiano, a qual sustenta o processo da dependência química, constituindo um ciclo que se retroalimenta, afetando as relações familiares, o trabalho e os vínculos de amizade dos adictos (ORTH; MORÉ, 2008). De acordo com o United Nations Office on Drugs and Crime, World Drug Report (2016), o número de pessoas descritas como "dependente de drogas" em todo o mundo aumentou de 27 milhões, em 2013, para 29 milhões, em 2014, destacando que cerca de 250 milhões de pessoas entre 15 e 64 anos usaram pelo menos uma droga em 2014.

A dependência de substâncias psicoativas "[...] escapa à racionalidade e aos mecanismos normais de tomada de decisão, e muitas vezes à própria noção de autopreservação" (TORRES; CHAGAS; RIBEIRO, 2008, p. 36). Seu consumo exagerado e sem regras é um complexo problema comportamental, no qual 0 indivíduo não se adapta às condições da existência social, com seus conflitos, perdas e ganhos, passando a emitir condutas desviantes e emocionalmente desreguladas que contribuem na adição (AMERICAN PSYCHIATRY ASSOCIATION, 2013; COSSIO-BOLAÑOS; ARRUDA; STUCCHI, 2009; TORRES; CHAGAS; RIBEIRO, 2008).

De acordo com Ribeiro e Laranjeira (2012), as políticas públicas voltadas para dependência química, de um modo geral, devem estabelecer parceiras com comunidades interessadas, investindo nos sistemas de tratamento, de reabilitação e reinserção social. Assim, com vistas a um modelo integral de atenção para usuários de drogas, foi homologada pela Portaria № 3.088, de 23 de dezembro de 2011 a Rede de Atenção Psicossocial (RAPS), que traz o modelo de atenção em saúde mental a partir do acesso e da promoção de direitos das pessoas baseados na convivência dessas pessoas dentro da sociedade, e busca a criação, ampliação e articulação de pontos de atenção à saúde aos usuários de crack, álcool e outras drogas no âmbito do SUS (BRASIL, 2011). Busca-se instaurar e desenvolver outros dispositivos além dos CAPS-ad, como: redes sociais e comunitárias; a atenção primária, notadamente a Estratégia de Saúde da Família; Centros de Convivência; Agentes Redutores de Danos; Serviço de Atendimento Móvel de Urgência; Unidades de Desintoxicação; Casas do Meio do Caminho; Hospital Clínico; Hospital Psiquiátrico; Pronto-Socorro (PS) de psiquiatria; hospitais-dia; moradias assistidas; e Comunidades Terapêuticas (CT) (Oliveira e Santos, 2010). A questão das comunidades terapêuticas tem sido bastante discutida em diversos órgãos, sendo vista por alguns como um retrocesso da política de drogas mais inclusiva, sendo 
atribuído a elas um caráter mais manicomial e de exclusão. 0 atual marco regulatório com a publicação das normas mínimas de funcionamento para esse ambiente de acolhimento é a Resolução CONAD n.․ 1 de 2015 (BRASIL, 2015).

Percebe-se que a questão das drogas é diversificada, complexa e multifacetada, ultrapassando motivações individuais e singulares, vinculando-se a facetas da vida social. Não teceremos juízo de valor no presente artigo sobre os dispositivos da RAPS, incluindo as comunidades terapêuticas, valendo a pena destacar Olivenstein (1985) quando destaca que, para compreendermos o fenômeno das drogas, precisamos considerar o tripé na determinação da drogadição: o sujeito, as drogas e o social. Portanto, em função da multideterminação e complexidade do fenômeno das drogas na atualidade, também se fazem necessários um olhar plural e intervenções múltiplas que abarquem o sujeito e suas singularidades, de forma multidisciplinar.

Diante disso, este estudo consiste em uma pesquisa multidisciplinar, que visou unir a área da Educação Física ao contexto da Saúde Mental-SM e investiga os significados que alguns jogos teatrais provocam em drogadictos, a partir das interações lúdicas proporcionadas ao brincar em aulas que consideram os indivíduos como produtores de linguagem e reconfiguradores de si mesmos junto com seu entorno existencial (CORREIA, 2015; GOMESDA-SILVA 2011, 2014; 2015), adotando a semiótica peirceana para organizar a produção pedagógica e didática das aulas, bem como interpretar seus resultados.

A Semiótica foi sistematizada como ciência a partir do final do século XIX, com duas tradições: a europeia e a norte-americana. A tradição europeia, mais conhecida pelas Ciências Humanas, compreende os fenômenos sociais como textos culturais ou sistemas linguísticos não verbais. Pertencente ao campo da Linguística, Ferdinand de Saussure (Suíça, 1857-1913) denominou tal ciência de Semiologia. Analisa a língua como um processo de significação a partir da relação imagem acústica (significante) e conceito (significado) - este é o signo linguístico, que serve de parâmetro para todas as outras relações sociais. A outra tradição semiótica, cujo precursor foi Charles Sanders Peirce (EUA, 1839-1914), mais reconhecida pelas pesquisas cognitivas, parte da lógica, compreendendo o universo físico, metafísico, psíquico ou social como processo de semiose - signos interconectados a outros signos, numa cadeia interminável de significação (PEIRCE, 1995). Optamos por esta formulação peirciana porque é a partir dela que nós pensamos a EF para além das dicotomias humanas e biológicas, e porque oferece um inventário categorial que contempla as dimensões estética, ética e lógica das práticas corporais.

O jogo teatral do método Viola Spolin contém uma estrutura estratégica organizada e orientada ao desenvolvimento de exercícios de colaboração na criação cênica e improviso. Esses jogos são capazes de promover momentos de gênese do improviso, em que o "Foco" e a proposição de ações físicas em cena são privilegiados no auxílio do contato direto com a linguagem teatral, facilitando 0 acesso às esferas da vida dos participantes, ao ponto de provocar-Ihes um estado de presença, por direcionar a atenção ao "aqui e agora" (KOUDELA, 1998, 2010). Spolin (2012b, p. 20) denomina esse estado de "tempo da descoberta, da criatividade, do aprendizado".

Faz-se necessário pontuar que, neste estudo, estabelecemos uma relação de integração entre os jogos teatrais do método Spolin e a estruturação da Aula Laboratório 
Pedagogia da Corporeidade aula-ALPC. Na abordagem da Pedagogia da Corporeidade'-PC, 0 jogo é entendido como pivô da aprendizagem que desejamos observar e produtor genuíno de linguagem, de significação, que permeia o processo ininterrupto de semiose, ou ação infinita do signo, e da possibilidade de gerar hábitos no comportamento desses jogadores (CORREIA, 2015; GOMES-DA-SILVA, 2011, 2014, 2015).

Acreditamos que durante os jogos teatrais é possível observar a geração de efeitos emocionais relacionados ao BES, provocados a partir do brincar. Adotamos como princípio norteador tanto a construção e vivência das ALPCs (GOMES-DA-SILVA, 2015), quanto a metodologia de observação e análise delas. Posto isso, a relação do jogo teatral, com seus elementos dramáticos: personagem, lugar e ação, somados ao seu Foco, dado na partida de jogo, formam a natureza única de uma relação triádica sígnica da investigação proposta por essa combinação integrada entre os jogos teatrais do método Viola Spolin e a estruturação da ALPC.

A CT Padre Ibiapina pesquisada situa-se em Alhandra/PB. É uma organização de cunho religioso, com gestão da Igreja Católica. Possui caráter de internato fechado, no qual seus membros só podem receber visitas de parentes no primeiro domingo de cada mês. Ao internar-se, todos recebem moradia, alimentação e auxílio religioso e psicológico, além de uma rotina de atividades laborais, tais como a produção de biscoitos e doces, plantio de alimentos, organização dos espaços, serviços domésticos e atividades religiosas, com horários predefinidos, para cumprirem semanalmente. Para manter-se interno é necessário que a família efetue pagamento mensal ou que arrecade o custeio do interno através da venda dos produtos por ele fabricados. 0 tempo de internato esperado é de um ano. A pesquisadora inseriu-se nesse contexto como professora participante e líder atuante da pesquisa após diálogo com a CTFE e assinatura da carta de anuência da pesquisa.

Posto isso, temos que os jogos teatrais têm a função de fazer emergir uma comunicação emotiva, gestual e reflexiva, a partir da criatividade surgida das interações entre os participantes, que, mediados pela linguagem teatral, se encontram engajados na solução cênica de um problema de atuação advinda do Foco dado no jogo (KOUDELA, 1998; SPOLIN, 2012a).

Desse modo, é possível pensar sobre a observação da corporeidade dos drogadictos manifesta nas interações em aula, no sentido de vivenciar situações de aprendizagem nas quais ocorram a experimentação de emoções, ações, inações e reflexões provocadas nas situações de movimento, com o intuito de ofertar a possibilidade aos jogadores de reelaborarem novas configurações de si, percebendo suas próprias emanações de significados durante o brincar. Essas situações gestadas devem possibilitar a manutenção de uma permanente conexão, conscientização e reconfiguração de si e do mundo que os cerca. Diante disto, o objetivo deste estudo foi investigar e descrever os significados relacionados ao Bem-estar Subjetivo relatados por drogadictos quando expostos a um programa de jogos teatrais dentro de um contexto de aula semiotizada.

1 Para o conhecimento do leitor a respeito da Pedagogia da Corporeidade, sugerimos as referências: CORREIA, S. N. C. Resenha do livro "O jogo da cultura e a cultura do jogo: por uma semiótica da corporeidade". Linguagem Acadêmica, v. 4, n. 2, p. 117-126, jul./dez. 2015. Disponível em: <http://claretianobt.com.br/download?caminho=/upload/cms/revista/sumarios/381.pdf\&arquivo=sumario7.pdf>. Acesso em: 30 ago. 2018. GOMES-DA-SILVA, P. N. O jogo da cultura e a cultura do jogo: por uma semiótica da corporeidade. João Pessoa: Editora Universitária da UFPB, 2011 e GOMES-DA-SILVA, P. N Pedagogia da corporeidade e seu epicentro didático: estruturação da aula laboratório. Rebescolar, ano 1, v. 1, ago. 2015. Disponível em: <https://www.rebescolar.com/Conpefe/PEDAGOGIA-DA-CORPOREIDADE-E-SEU-EPICENTRODID\%C3\%81TICO\%3A-estrutura\%C3\%A7\%C3\%A30-da-aula-laborat\%C3\%B3rio>. Acesso em: 30 ago. 2018. 


\section{PROCEDIMENTOS METODOLÓGICOS}

Trata-se de uma pesquisa com abordagem qualitativa do tipo investigação-ação (THIOLLENT, 1988), que consistiu na vivência de um programa composto de quatro aulas de jogos teatrais do método Viola Spolin (2012b), sob a estruturação da Pedagogia da Corporeidade, sendo uma por semana, aos sábados, com duas horas de duração cada. Participaram deste estudo ao total 18 internos da parte masculina da CTFE na cidade de Alhandra/PB. Desses 18 , os que tiveram frequência igual ou superior a três aulas foram selecionados para que seus dados fossem analisados, restando, assim, cinco participantes entrevistados. Os dados obtidos desses cinco participantes compuseram os resultados, discussão e conclusão.

O programa configurou-se em uma ALPC inicial, didático-exploratória para compreensão da dinâmica de aula com a PC, estruturada em Sentir, Reagir e Refletir, bem como experimentação prática de jogos teatrais. Foi inserido o "Jogo do Quem", específico para aprendizagem de personagens. Também foi apresentado, explicado e experimentado o Roteiro de Observação da aula. Na segunda ALPC foi experimentado o "Jogo do Onde" para introduzir o desenvolvimento de cenas de lugares. Na terceira ALPC foi dinamizado o jogo do "O que faço com..." para aprendizagem de ações físicas em um tempo e lugar dentro de uma dinâmica fictícia. Na quarta ALPC foram trabalhados os jogos "Construindo uma história" e "Fazendo parte do todo" para criação de cenas integradas com os demais elementos cênicos e evolução da interação entre personagens. Todas as ALPCs tiveram três fases: Sentir, Reagir e Refletir, nas quais propunhase interações do tipo conhecer, agir e desenhar, respectivamente, seus aprendizados. Em todas as ALPCs, durante a fase de Refletir, houve atividades de pintura como meio de registro de informações sobre possíveis aprendizados resultantes da vivência proposta.

Os instrumentos utilizados para coleta de dados foram o Roteiro de Observação da ALPC, que consistiu da composição de indicadores correspondentes a ações executadas nos três momentos que compõem a ALPC, e o RES-Roteiro de Entrevista Semiestruturada, que visou conhecer os significados de emoções e possíveis modificações que ocorreram em suas vidas ao longo da vivência no programa de jogos. As entrevistas foram realizadas individualmente pela professora-pesquisadora, com a técnica de gravação em áudio.

O roteiro de observação continha três categorias:1-Interação, 2-Implicação e 3-Integração. Dentro dessas categorias existia uma pergunta, respectivamente: A- De que forma os jogadores se comunicaram, uns com os outros, com todo o espaço e objetos, por meio da voz e ações em cena?; B- De que forma os jogadores conseguiram criar ações e improvisar junto com os colegas durante o jogo?; e C-De que forma os jogadores agiram com verdade e naturalidade uns com os outros no jogo? Para a categoria 1, os jogadores podiam responder à pergunta A com os seguintes indicadores: "silenciou", "sentiu", "olhou", "ouviu", "esperou", "entendeu", "se dispôs", "pausou", "respondeu", "se expôs", "usou a voz", "se deslocou", "percebeu o ambiente e objetos", "comunicou-se com o ambiente e objetos", "relacionou-se". Para a categoria 2, os jogadores podiam responder à pergunta $\mathrm{B}$ com os seguintes indicadores: "manteve o foco", "propôs ações", "inventou", "pertenceu ao todo". Para a categoria 3, os jogadores podiam responder à pergunta $\mathrm{C}$ com os seguintes indicadores: "foi espontâneo", "esteve presente no aqui e agora", "pareceu real".

Esses indicadores presentes no Roteiro de Observação da ALPC foram sinalizados por todos os jogadores durante a avaliação da cena, sendo posteriormente revisados e 
comparados à avaliação por vídeo, realizada posteriormente pela professora-pesquisadora. As ações efetivadas na partida de jogo foram categorizadas a partir da análise em vídeo e correspondem às unidades de registro. E os indicadores contidos no Roteiro de Observação da ALPC sinalizados pelos jogadores resultaram nas subunidades de registro.

Para podermos descrever com mais detalhes os significados gerados pelo jogo teatral dentro da ALPC, foi escolhida a quinta cena/partida realizada no jogo "Parte do Todo \#2", proposto na quarta ALPC, por conter uma estrutura na qual cada jogador precisava ora propor ações individuais, ora fazer-se parte de ações propostas por outro jogador em cena para que fosse possível a construção de um diálogo no improviso cênico.

Da zona de corporeidade manifesta nessa cena/partida, ou seja, do contexto de configuração da manifestação interativa dos gestos no jogo, obtiveram-se as categorias analíticas resultantes.

Todas as informações coletadas e descritas em quadro foram apreciadas por meio da Análise de Conteúdo de Bardin (1987). Para a análise dos significados provocados nos jogadores foi realizada uma análise semiótica.

\subsection{Autorrelato e o bem-estar subjetivo}

de acordo com a literatura, "o método mais usual de mensuração do BES consiste no uso do autorrelato, no qual o indivíduo julga sua satisfação com relação à sua vida e relata a frequência de emoções afetivas recentes de prazer e desprazer" (DIENER, 1984; SCORSOLINICOMIN; SANTOS, 2010, p. 444). Para Albuquerque e Tróccoli (2004), os autorrelatos parecem ser o que existe de mais apropriado para conhecer o BES, pois consideram o sentimento direto do indivíduo acerca da experimentação de seus prazeres e desprazeres e sobre o que ele julga estar satisfatório ou não na sua vida.

\subsection{Aspectos éticos}

esta pesquisa atende aos novos preceitos regulamentares das pesquisas que envolvem seres humanos, dispostos na Resolução nํ. 466/2012 do CNS, e foi aprovada pelo CEP do CCS da UFPB, sob o Parecer Final $n \div$. 1.080.746, e teve a assinatura de todos os participantes do Termo de Consentimento Livre e Esclarecido.

\section{RESULTADOS E DISCUSSÃO}

Como explicado anteriormente, como nem todos os 18 jogadores participaram de todas as ALPCs juntos, os resultados foram analisados e explicados baseando-se apenas nos dados fornecidos pelos jogadores que passaram no critério de ter participado ao menos de três ALPCs. Estes revelaram uma idade média de 22 anos e 7 meses, sendo quatro participantes naturais de João Pessoa/PB e um de Goiana/PE, solteiros, apenas um tinha filho, três haviam concluído o ensino médio, um tinha o ensino superior incompleto e um o ensino fundamental incompleto, com profissões diversas (borracheiro, comerciante, porteiro e eletricista). Os demais não tiveram suas fichas e instrumentos avaliados.

Dentre os avaliados, houve relato de consumo anterior para as seguintes drogas: cigarro, álcool, maconha, crack, cocaína, cola, éter, LSD, ecstasy, ansiolíticos, anfetaminas 
e derivados. Foi sinalizado o uso para várias dessas substâncias de uma só vez. O tempo de morada médio na fazenda era de quatro meses. Os participantes não referiram conhecimento anterior por jogos teatrais.

\subsection{Efeito do jogo teatral sobre o bem-estar subjetivo de drogadictos}

apresentamos no Quadro 1 a exposição dos significados emocionais, apresentados pelos participantes, que as ações físicas, realizadas por meio do improviso nas interações durante a análise de cena no jogar, ocasionaram sobre o BES dos drogadictos avaliados.

Quadro 1 - Análise de conteúdo dos significados emocionais relatados com mais frequência

\begin{tabular}{|l|l|l|l|}
\hline $\begin{array}{l}\text { Categoria } \\
\text { empírica }\end{array}$ & $\begin{array}{l}\text { Unidade de } \\
\text { contexto }\end{array}$ & $\begin{array}{l}\text { Unidades de } \\
\text { registro por aula }\end{array}$ & $\begin{array}{l}\text { Unidades de registro após intervenção } \\
\text { final }\end{array}$ \\
\hline \multirow{2}{*}{$\begin{array}{l}\text { Relatos } \\
\text { de emoções }\end{array}$} & \multirow{2}{*}{ Bem-Estar Subjetivo } & Bem-estar & Bem-estar \\
\cline { 3 - 4 } & & $\begin{array}{l}\text { Liberdade para se } \\
\text { expressar }\end{array}$ & Felicidade \\
\cline { 3 - 4 } & & Sentir-se vinculado ao grupo \\
\hline
\end{tabular}

Fonte: Elaboração própria

Albuquerque e Tróccoli (2004), assim como Siqueira e Padovan (2008), consideram que o BES necessariamente apresenta três características que o distinguem de outros conceitos: a subjetividade (experiência interna de cada indivíduo), as medidas positivas (predominância dos afetos positivos sobre os negativos) e a avaliação global (avaliação dos diversos aspectos da vida de uma pessoa). Os afetos são considerados como sentimentos ou um estado emocional transitório de prazer, nos quais emoções positivas (como alegria, calma, bem-estar, paz, otimismo, entre outras) e negativas (como ansiedade, depressão, agitação, pessimismo, entre outras) são experimentadas e postas na balança do julgamento sobre a satisfação global da vida. Juntas, essas características compõem o BES (FERRAZ; TAVARES; ZILBERMAN, 2007; OTTA; FIQUER, 2004).

Os significados que resultaram em emoções positivas de Bem-estar, Alegria e Felicidade podem ser observados por meio do exemplo da fala do Jogador 4, que relata: "Senti alegria e bem-estar em todos os jogos. Bem-estar, porque os jogos nos levam à essência do nosso ser. Na espontaneidade passamos quem somos de verdade. Fiquei muito feliz em saber que aconteceriam estes jogos aqui. Porque me encontro cada dia comigo mesmo, e assim cresço e evoluo".

O Jogador Participante 5, por sua vez, relatou sentir "um destravamento, um desbloqueio, pois apesar d'eu ser bem comunicativo, eu me sentia bloqueado por uso das drogas. Com as brincadeiras eu pude me destravar mais, me deslocar mais, quebrar barreiras que antes só quando criança".

Notamos nesses relatos que as aulas com jogos teatrais do método Viola Spolin, estruturadas pela PC, possibilitaram alcance terapêutico por oportunizar aos jogadores um processo de reconhecimento e liberação de emoções reprimidas, originando um sentimento de alívio, possivelmente causado pela consciência e ressignificação de sentimentos vividos 
anteriormente, fazendo com que eles fossem capazes de perceber a conexão do uso das drogas e sua ligação com emoções negativas reprimidas.

Outro exemplo, correlacionado à manifestação do efeito de Felicidade conjuntamente ou consequentemente a Sentir-se vinculado ao grupo, foi sentido e representado na fala do Jogador Participante 1, em sua quarta sessão, ao dizer que "Hoje o que me mostrou foi a felicidade da gente se sentar e assistir um jogo de futebol, todo mundo reunido... e me motivou muito ter assistido o jogo da família completa, assim: 'A Família Esperança' junto com a Sara". Essa fala demonstra aspectos de felicidade e satisfação por ter conseguido estabelecer uma conexão de confiança com os colegas de jogo, a partir do jogo realizado na quarta aula.

Spolin (2012a) realça que nos jogos que trabalham com o Foco na construção de ações que são divisões de uma ação maior, como o jogo "Parte do Todo", por exemplo, o jogador experimenta um sentido de pertencimento e conexão com todos os demais executantes da cena, resultando em um efeito de vinculação ao grupo. Consequentemente, esse efeito emocional tende a favorecer o sentimento de desvinculação emocional sentido pelos drogadictos, fortalecendo, assim, a manifestação da consciência acerca de se sentirem pertencentes a algo ou capazes de desenvolver relações próximas com seus pares, mesmo que em virtude da participação momentânea em um programa de jogos, ofertado a partir de um contexto de interação didático-científica.

Os vínculos consistem em uma estrutura dinâmica que se organiza na relação estabelecida entre os diversos atores envolvidos em uma situação. Essas relações interpessoais, que, para o nosso caso, foram coletivas, dependem do fluir entre as ações de assumir a função de um papel social e respeitar as ações advindas em função do papel assumido pelo outro (MORAES et al., 2010; SOUZA; KANTORSKI; MIELKE, 2006).

Outros significados foram relatados entre os jogadores, a exemplo da Sensação de liberdade para se expressar, a qual pode representar a manifestação emotiva de estar fazendo algo prazeroso e satisfatório a fim de melhorar a si mesmo, conforme explicita o Jogador Participante 3, dizendo que "pra mim foi o mais divertido que teve até agora, me senti à vontade, interagi com todos e pude expressar o máximo de mim. Senti sensações legais, alegria". Com relação a esta mesma aula, o Jogador Participante 5 menciona que "o jogo hoje foi bacana, estimulou a nossa criatividade, faz com que a gente utilize o que utilizava lá fora como algo negativo, utilize aqui dentro com uma coisa bem produtiva, bem positiva e ajuda a nos liberar de outra forma".

Por conseguinte, quando questionados sobre o porquê de se sentiram bem após realizar todo o programa de jogos, ouvimos relatos de significados positivos dos jogadores, como o exemplo do Jogador Participante 3, quando menciona que "foi divertido os momentos, gerou mais um laço de amizade entre eu e os meninos, que alguns são um pouco afastados, sempre tem isso aqui. Foi bom pra aproximar, querendo ou não, aproxima mais as pessoas". Com isso, confirma-se que tais jogos proporcionam novas possibilidades de aproximação com o outro, bem como o fortalecimento de vínculos anteriormente estabelecidos.

A exemplo da manifestação de sentimentos de amizade e aproximação dos vínculos sociais, um estudo realizado por Santos, Oliveira e Souza (2013) aplicou um programa de jogos de estratégia com grupos de drogadictos em processo de reabilitação, tendo sido descoberto que, após jogar, eles demonstravam maior iniciativa para a tomada de decisões e resolução de 
problemas. Como resultado da participação nesse programa, os drogadictos conseguiram se conhecer melhor, aceitar mais o outro com suas diferenças, criar novos vínculos de amizade e aumentar a capacidade de desenvolver melhores estratégias para resolver os problemas surgidos no jogo.

Outros pesquisadores referenciam que atividades planejadas com o cunho de lazer podem servir para orientar e disciplinar drogadictos quanto ao estabelecimento de estruturação das atividades diárias em seu tratamento e, posteriormente, na absorção dessa estrutura para a sua vida após processo de tratamento (AHN et al., 2014).

Os jogadores também foram questionados, durante a entrevista final, se as vivências dos jogos ofertadas diminuíam a necessidade de usar drogas. Conforme o que descreve 0 Jogador Participante 4, "Já fazem seis meses que não uso drogas. Os jogos não ajudam a diminuir nada e sim nos dão um caminho diferente a seguir". De acordo com essa fala, acentuase que esse programa com jogos teatrais demonstrou ser uma possibilidade de ajuda para enfrentar o período de abstinência e se manter mais estável durante o processo de tratamento dentro da CTFE.

Diante de tudo o que aqui foi exposto, compreende-se que o jogo pode surgir como uma possibilidade de provocar emoções que venham a produzir significados de sensação de amparo e diminuição da ansiedade, contribuindo para a formação de vínculos socioafetivos, produzindo sentimentos, mesmo que temporários, de liberdade, alegria, vinculação, felicidade e bem-estar. Esses podem ser entendidos como possíveis fatores para estabelecimento de uma relação de segurança emocional com seus pares e professor, e até com o próprio jogo, na medida em que causam a gênese de tais efeitos emotivos e vão contra o comportamento adicto, que apresenta tendência ao isolamento e depressão, desconforto pela ansiedade para consumir a droga, entre outros aspectos (FERREIRA, TUFIK; MELO, 2001).

Quanto à experimentação de emoções negativas advindas da participação nos jogos, foram encontrados sentimentos de timidez, raiva e inibição no Jogador Participante 3. Essas emoções não foram julgadas por nós como efeitos negativos porque tratavam, na verdade, da expectativa em relação ao próprio desempenho e da autorreflexão acerca do próprio desenvolvimento em cena durante o jogar, evidenciando mais um estado de autocrítica e reflexão com relação à escolha de ações e colaborações expressadas no jogo.

O Jogador Participante 5 relatou emoções de desconforto e constrangimento por não conseguir realizar os jogos, pelo motivo da aparente obesidade. Essa emoção, embora entendida como negativa, deve servir para se proporem mudanças no sentido de oferecer uma revisão do tipo de jogo, ou mesmo em adaptações na forma de jogar e na maneira como se expõem os objetivos do jogo, ou até na maneira de lidar com o próprio excesso de peso ou dificuldade surgida no percurso da execução da atividade proposta.

É importante destacar que, mesmo com a presença de emoções negativas sentidas e manifestadas entre os relatos dos jogadores, foi possível observar que o êxito na participação no programa superou as más expectativas previamente existentes entre os jogadores, e que a expressão de emoções positivas, com reais efeitos positivos, foram a tônica encontrada entre os jogadores durante toda a intervenção programada.

Entre os internos na CTFE que tiveram oportunidade de vivenciar experiências de situações de movimento com jogos teatrais na ótica da PC, foi possível verificar a manifestação 
de emoções positivas que oportunizaram a esses jogadores participantes deslocarem sua atenção para a percepção de que há um caminho em que podem construir afetos saudáveis uns para com os outros. Acreditamos que, se houvesse a oportunidade de continuarem experimentando mais aulas com essa perspectiva pedagógica, possivelmente seriam gerados mais sentimentos de alegria, bem-estar, felicidade, sensação de estarem mais vinculados afetiva e socialmente aos membros do grupo de convivência residencial, e que, consequentemente, tais momentos de sentimentos positivos ajudariam no processo de tratamento e abstinência por meio da mudança nos hábitos de pensar, agir e refletir, facilitando um repensar sobre a lógica do viver sem a necessidade do uso constante de substâncias psicoativas.

\section{CONCLUSÃO}

Apontamos como descobertas significativas a geração dos significados de Bemestar Subjetivo relatados através das sensações de bem-estar, sensação de liberdade para se expressar, alegria, felicidade e sentir-se vinculado ao grupo, provocados pelo jogo teatral, a partir da interação lúdica entre jogadores, professora-pesquisadora e ambiente. Com isso, verificamos a real possibilidade de serem trabalhados conteúdos pertinentes à SM, tais como emoções de felicidade e bem-estar, criação de vínculos, amizade, sensação de pertencimento, entre outros, por meio de vivências específicas e direcionadas aos problemas inerentes aos drogadictos, sob a lógica didático-pedagógica da PC.

Outras manifestações de ações e emoções foram ainda relatadas entre os jogadores, tais como: melhoria na comunicação e aproximação com o outro, autorreflexão sobre a vida, parcimônia para lidar e conviver melhor com o outro, geração de sentimento de maior amizade, além do desenvolvimento de uma conduta mais lúdica e grata quanto à realização das tarefas do quotidiano dentro da CTFE. Acreditamos que esses sentimentos podem ter incidido diretamente na percepção do desempenho nos jogos, determinando, assim, os relatos encontrados entre os jogadores, gerando influência significativa na manifestação dos sentimentos mais frequentes de bem-estar e felicidade.

Sendo assim, o programa de jogos teatrais representou uma alternativa inovadora de auxílio no processo de recuperação de drogadictos. Por se tratar de uma atividade expressiva, contém o apelo para o uso dos recursos corporal, vocal e da criatividade, que permitem manifestar sensações de forma espontânea, livre e sem julgamentos e oportunizam aos jogadores perceberem-se possuidores de criatividade, escolhas, decisões, expressão de gestos e voz, resultando na capacidade de gestar sentimentos e observar seu próprio acervo de sensações, emoções e sentimentos prazerosos e positivos, capazes de proporcionar mudanças no rumo dos acontecimentos dentro do jogo, e possivelmente, mais tarde e com mais prática, na própria vida. Entretanto, sugere-se ainda que outras pesquisas sejam realizadas, ampliando a experiência com outros drogadictos e em outros contextos de inserção. 


\section{REFERÊNCIAS}

AHN, Chan-Woo et al. A study on the development of the protocol of leisure activity program for the elderly's deviant prevention. Journal of Exercise Rehabilitation, v. 10, n. 2, p. 106-110, 2014.

ALBUQUERQUE, Anelise Salazar; TRÓCCOLI, Bartholomeu Tôrres. Desenvolvimento de uma Escala de Bem-Estar Subjetivo. Psicologia: Teoria e Pesquisa, v. 20, n. 2, p. 153-164, maio/ago. 2004. Disponível em: <http://www.scielo.br/pdf/ptp/v20n2/a08v20n2>. Acesso em: 30 ago. 2018.

AMERICAN PSYCHIATRY ASSOCIATION. Diagnostic and Statistical Manual of Mental disorders: DSM-5. $5^{\text {th }}$. ed. Washington, 2013.

BARDIN, Laurence. Análise de conteúdo. Lisboa: Edição 70, 1987.

BRASIL. Ministério da Saúde. Portaria nº 3.088, de 23 de dezembro de 2011. Institui a Rede de Atenção Psicossocial para pessoas com sofrimento ou transtorno mental e com necessidades decorrentes do uso de crack, álcool e outras drogas, no âmbito do Sistema Único (SUS). Diário Oficial da União, Brasília, DF, no․ 247, Seção 1, p. 230-232, 26 dez. 2011.

BRASIL. Resolução № 1, de 19 de agosto de 2015. Regulamenta, no âmbito do Sistema Nacional de Políticas Públicas sobre Drogas (Sisnad), as entidades que realizam o acolhimento de pessoas, em caráter voluntário, com problemas associados ao uso nocivo ou dependência de substância psicoativa, caracterizadas como comunidades terapêuticas. Diário Oficial da União, Brasília, DF, no165, Seção 1, p. 51, 28 ago.2015.

CLASSIFICAÇÃO de Transtornos Mentais e de Comportamento da CID-10: Descrições Clínicas e Diretrizes Diagnósticas. Trad. Dorgival Caetano. Porto Alegre: Artmed, 1993.

CORREIA, Sara Noêmia Cavalcanti. Resenha do livro "O jogo da cultura e a cultura do jogo: por uma semiótica da corporeidade”. Linguagem Acadêmica, v. 4, n. 2, p. 117-126, jul./dez. 2015.

COSSIO-BOLAÑOS, Marco; ARRUDA, Miguel; STUCCHI, Sérgio. Dependência química e sua relação com a atividade física. Revista Brasileira Ciências da Saúde, v. 7, n. 21, p. 20-33, jul./set. 2009.

DIENER, Ed. Subjective well-being. Psychological Bulletin, v. 95, n. 3, p. 542-575, 1984.

FERRAZ, Renata Barbosa; TAVARES, Hermano; ZILBERMAN, Mônica. Felicidade: uma revisão. Revista de Psiquiatria Clínica, v. 34, n.5, p. 234-242, 2007.

FERREIRA, Sionaldo Eduardo; TUFIK, Sérgio; MELO, Marco Túlio. Neuroadaptação: uma proposta alternativa de atividade física para usuários de drogas em recuperação. Revista Brasileira de Ciências e Movimento, v. 9, n. 1, p.31-39, 2001.

GOMES-DA-SILVA, Pierre Normando. 0 jogo da cultura e a cultura do jogo: por uma semiótica da corporeidade. João Pessoa: Editora Universitária da UFPB, 2011.

GOMES-DA-SILVA, Pierre Normando. Pedagogia da corporeidade e seu epicentro didático: estruturação da aula laboratório. Rebescolar, v. 1, n. 1, p. 17-37, ago. 2015. Disponível em: $<$ thtps://www.rebescolar.com/Conpefe/PEDAGOGIA-DA-CORPOREIDADE-E-SEU-EPICENTRODID\%C3\%81TICO\%3A-estrutura\%C3\%A7\%C3\%A3o-da-aula-laborat\%C3\%B3rio>. Acesso em: 22 ago. 2018. 
GOMES-DA-SILVA, Pierre Normando. Pedagogia da corporeidade: 0 decifrar e o subjetivar na educação. Revista Tempos e Espaços em Educação, v.13, p. 22-43, maio/ago. 2014. Disponível em <http://www.seer.ufs.br/index.php/revtee/article/view/3255/2874>. Acesso em: 30 ago. 2018.

GONÇALVES, Elias Correia. Alguns conceitos referentes à toxicomania. In: BUCHER, Richard Emil (Org.). As drogas e a vida. São Paulo: EPU, 1988. p. 69-89.

KOUDELA, Ingrid Dormien. Apresentação do dossiê jogos teatrais no Brasil: 30 anos. Revista de história e estudos culturais, v. 7, n.1, p. 01-33, jan./abr. 2010.

KOUDELA, Ingrid Dormien. Jogos teatrais. São Paulo: Perspectiva, 1998.

MORAES, Denise Pena et al. Redes Sociais: um estudo de caso sobre a Fazenda da Esperança. RISUS- Journal on Innovation and Sustainability, v. 1, n. 1, 2010. Disponível em: <http://revistas. pucsp.br/index.php/rad/article/view/2938>. Acesso em: 30 ago. 2018.

OLIVEIRA, Evaldo Melo; SANTOS, Nara Tavares Veloso. A rede de assistência aos usuários de álcool e outras drogas - em busca da integralidade. In. SANTOS, L. M. B. (Org.). Outras palavras sobre o cuidado de pessoas que usam drogas. Porto Alegre: Ideograf, 2010. p. 71-86.

OLIVENSTEIN, Claude. Destino do Toxicômano. São Paulo: Almed, 1985.

ORTH, Anaídes Pimentel da Silva; MORÉ, Carmén Leontina Ojeda Ocampo. Funcionamento de famílias com membros dependentes de substâncias psicoativas. Psicologia e Argumento, v. 26, n. 55, p. 293-303, out./dez. 2008.

OTTA, Emma; FIQUER, Juliana Teixeira. Bem-Estar Subjetivo e regulação de emoções. Psicologia em Revista, v. 10, n. 15, p. 144-149, jun. 2004. Disponível em: <http://www.pucminas.br/imagedb/ documento/DOC DSC NOME ARQUI20041213115707.pdf>. Acesso em: 07 jan. 2016.

PEIRCE, Charles Sanders. Semiótica. São Paulo: Perspectiva, 1995.

RIBEIRO, Marcelo; LARANJEIRA, Ronaldo. 0 tratamento do usuário de crack. 2. ed. Porto Alegre: Artmed, 2012.

SANTOS, Carlos; OLIVEIRA, José Reis; SOUZA, Amanda Maria. O uso dos jogos no processo de reabilitação dos dependentes químicos. In: MOSTRA INTEGRADA DE INICIAÇÃO CIENTÍFICA CNEC, 4.,2013, Osório-RS. Anais..., Osório, v. 4, n. 4, jun. 2013. Disponível em: <http://facos.edu. br/publicacoes/revistas/anais mostra integrada de iniciacao cientifica/julho 2013/pdf/o uso dos jogos no processo de reabilitacao dos dependentes quimicos.pdf>. Acesso em: 30 ago. 2018.

SCORSOLINI-COMIN, Fábio; SANTOS, Manoel Antônio. Avaliação do Bem-Estar Subjetivo (BES): Aspectos Conceituais e Metodológicos. Revista Interamericana de Psicologia, v. 44, n. 3, p. 442-448, 2010. Disponível em: <http://www.redalyc.org/articulo.oa?id=28420658005>. Acesso em: 30 ago. 2018.

SIQUEIRA, Mirlene Maria Matias; PADOVAM, Valquíria Aparecida Rossi. Bases Teóricas de BemEstar Subjetivo, Bem-Estar Psicológico e Bem-Estar no Trabalho. Psicologia: Teoria e Pesquisa, Brasília-DF: v. 24, n. 2, p. 201-209, 2008. Disponível em: <http://www.scielo.br/pdf/ptp/v24n2/09>. Acesso em: 22 ago. 2018.

SOUZA, Jacqueline; KANTORSKI, Luciane Prado; MIELKE, Fernanda Barreto. Vínculos e redes sociais de indivíduos dependentes de substâncias psicoativas sob tratamento em CAPS AD. SMAD, Revista Eletrônica Saúde Mental Álcool Drogas, v.2, n.1, p. 01-17, fev. 2006. Disponível em: $<$ http://pepsic.bvsalud.org/pdf/smad/v2n1/v2n1a03.pdf>. Acesso em: 30 ago. 2018. 
SPOLIN, Viola. Jogos teatrais na sala de aula: um manual para o professor. Trad. Ingrid Dormien Koudela. São Paulo: Perspectiva, 2012a.

SPOLIN, Viola. Jogos teatrais: o fichário de Viola Spolin. Trad. Ingrid Dormien Koudela. São Paulo: Perspectiva, 2012b.

THIOLLENT, Michel. Metodologia da pesquisa-ação. São Paulo: Cortez, 1988.

TORRES, Nuno Manuel Correia; CHAGAS, Tiago.; RIBEIRO, João Paulo. Dependência emocional e consumo de substâncias psicoactivas: Um estudo correlacional a partir da teoria dos grupos de pressuposto básico de W. R. Bion. Toxicodependências, v. 14, n. 3, p. 35-48, 2008.

UNITED NATIONS OFFICE ON DRUGS AND CRIME. World Drug Report. New York: United Nations: Sales, 2016. 
